University of Nebraska - Lincoln

DigitalCommons@University of Nebraska - Lincoln

\title{
Chlorella virus ATCV-1 encodes a functional potassium channel of 82 amino acids
}

\author{
Sabrina Gazzarrini \\ Università degli Studi di Milano \\ Ming Kang \\ University of Nebraska-Lincoln, mkang2@unl.edu \\ Alessandra Abenavoli \\ Università degli Studi di Milano \\ Giulia Romani \\ Università degli Studi di Milano \\ Claudio Olivari \\ Università degli Studi di Milano \\ See next page for additional authors
}

Follow this and additional works at: https://digitalcommons.unl.edu/plantpathpapers

Part of the Plant Pathology Commons

Gazzarrini, Sabrina; Kang, Ming; Abenavoli, Alessandra; Romani, Giulia; Olivari, Claudio; Gaslini, Daniele; Ferrara, Giuseppina; Van Etten, James L.; Kreim, Michael; Kast, Stefan M.; Thiel, Gerhard; and Moroni, Anna, "Chlorella virus ATCV-1 encodes a functional potassium channel of 82 amino acids" (2009). Papers in Plant Pathology. 207.

https://digitalcommons.unl.edu/plantpathpapers/207

This Article is brought to you for free and open access by the Plant Pathology Department at DigitalCommons@University of Nebraska - Lincoln. It has been accepted for inclusion in Papers in Plant Pathology by an authorized administrator of DigitalCommons@University of Nebraska - Lincoln. 


\section{Authors}

Sabrina Gazzarrini, Ming Kang, Alessandra Abenavoli, Giulia Romani, Claudio Olivari, Daniele Gaslini, Giuseppina Ferrara, James L. Van Etten, Michael Kreim, Stefan M. Kast, Gerhard Thiel, and Anna Moroni 
Published in Biochemical Journal 420 (2009), pp. 295-303; doi:10.1042/BJ20090095 Copyright ( 2009 Sabrina Gazzarrini, Ming Kang, Alessandra Abenavoli, Giulia Romani, Claudio Olivari, Daniele Gaslini, Giuseppina Ferrara, James L. van Etten, Michael Kreim, Stefan M. Kast, Gerhard Thiel, and Anna Moroni.

Submitted January 14, 2009; revised February 19, 2009; accepted March 6, 2009; published online March 6, 2009.

\title{
Chlorella virus ATCV-1 encodes a functional potassium channel of 82 amino acids
}

\author{
Sabrina Gazzarrini, ${ }^{1}$ Ming Kang, ${ }^{2}$ Alessandra Abenavoli, ${ }_{1}$ Giulia Romani, ${ }^{1}$ Claudio Olivari, ${ }^{1}$ Daniele Gaslini, ${ }^{1}$ \\ Giuseppina Ferrara, ${ }^{1}$ James L. van Etten, ${ }^{2}$ Michael Kreim, ${ }^{3,4}$ Stefan M. Kast, ${ }^{3}$ Gerhard Thiel, ${ }^{4}$ and Anna Moroni ${ }^{1}$ \\ ${ }^{1}$ Department of Biology and CNR - Istituto di Biofisica, Università degli Studi di Milano, Via Celoria 26, 20133 Milano, Italy \\ ${ }^{2}$ Department of Plant Pathology and Nebraska Center for Virology, University of Nebraska-Lincoln, Lincoln, NE 68583-0900, U.S.A. \\ ${ }^{3}$ Eduard-Zintl-Institut für Anorganische und Physikalische Chemie, Technische Universität Darmstadt, Petersenstrasse 20, Darmstadt, Germany \\ ${ }^{4}$ Institute of Botany, Technische Universität Darmstadt, Schnittspahnstrasse 3, D-64287 Darmstadt, Germany \\ Corresponding author - A. Moroni, e-mail anna.moroni@unimi.it
}

\begin{abstract}
Chlorella virus PBCV-1 (Paramecium bursaria chlorella virus-1) encodes the smallest protein (94 amino acids, named Kcv) previously known to form a functional $\mathrm{K}^{+}$channel in heterologous systems. In this paper, we characterize another chlorella virus encoded $\mathrm{K}^{+}$channel protein $(82$ amino acids, named ATCV-1 Kcv) that forms a functional channel in Xenopus oocytes and rescues Saccharomyces cerevisiae mutants that lack endogenous $\mathrm{K}^{+}$uptake systems. Compared with the larger PBCV-1 Kcv, ATCV-1 Kcv lacks a cytoplasmic N-terminus and has a reduced number of charged amino acids in its turret domain. Despite these deficiencies, ATCV-1 Kcv accomplishes all the major features of $\mathrm{K}^{+}$channels: it assembles into a tetramer, is $\mathrm{K}^{+}$selective and is inhibited by the canonical $\mathrm{K}^{+}$channel blockers, barium and caesium. Single channel analyses reveal a stochastic gating behavior and a voltage-dependent conductance that resembles the macroscopic $I / V$ relationship. One difference between PBCV-1 and ATCV$1 \mathrm{Kcv}$ is that the latter is more permeable to $\mathrm{K}^{+}$than $\mathrm{Rb}^{+}$. This difference is partially explained by the presence of a tyrosine residue in the selective filter of ATCV-1 Kcv, whereas PBCV-1 Kcv has a phenylalanine. Hence, ATCV-1 Kcv is the smallest protein to form a $\mathrm{K}^{+}$channel and it will serve as a model for studying structure-function correlations inside the potassium channel pore.
\end{abstract}

Keywords: chlorella virus ATCV-1, Kcv, $\mathrm{K}^{+} / \mathrm{Rb}^{+}$selectivity, phycodnavirus, viral $\mathrm{K}^{+}$channel, yeast complementation

Abbreviations: ORF, open reading frame; PBCV-1, paramecium bursaria chlorella virus-1; TM, transmembrane domain

\section{Introduction}

Phycodnaviruses [1-4] consist of a genetically diverse, but morphologically similar, group of large dsDNA (doublestranded DNA)-containing viruses (170-560 kb) that infect algae from both fresh and marine waters [5,6]. The most studied phycodnaviruses are the plaque-forming chlorella viruses that infect certain freshwater, unicellular, eukaryotic, chlorella-like green algae $[7,8]$. Chlorella viruses encode up to 400 proteins of which $35-40 \%$ resemble entries in the public databases. Many chlorella virus encoded proteins are either the smallest or among the smallest representatives of their functional class. Consequently, some of the chlorella virus encoded proteins are the subject of intense physical and biochemical investigations. One example is the chlorella virus PBCV-1 (Paramecium bursaria chlorella virus-1) encoded 94-amino-acid $\mathrm{K}^{+}$channel protein, named $\mathrm{Kcv}$, which forms functional channels in Xenopus oocytes [9], Chinese-hamster ovary cells [10] and HEK293 cells (human embryonic kidney cells) [11]. The PBCV-1 $\mathrm{Kcv}$ structure is truly minimal: the channel monomer consists of two TMs (transmembrane domains), a pore loop and a 12amino-acid cytoplasmic N-terminus. Like other $\mathrm{K}^{+}$channels, PBCV-1 Kcv forms a functional tetramer [12] and electrophysiology experiments established that PBCV-1 Kcv has many properties similar to more complex $\mathrm{K}^{+}$channels, including gating, selectivity, sensitivity to voltage and susceptibility to channel blockers [9]. These results imply that these functional properties are inherent in the structure of the protein.

Kcv-like genes were cloned and expressed from 40 additional viruses that infect the same host, Chlorella NC64A; 16- amino-acid substitutions occurred among the 94 amino acids, producing six new $\mathrm{Kcv}$-like proteins that formed functional $\mathrm{K}^{+}$ selective channels in Xenopus oocytes. However, the biophysical properties of some of these $\mathrm{Kcv}$ channels differed from PBCV-1 Kcv, including altered current kinetics with $\mathrm{K}^{+}$and $\mathrm{Rb}^{+}$and altered sensitivity to channel blockers $[13,14]$. Even more diversity is found between $\mathrm{K}^{+}$channel proteins from chlorella viruses with different hosts. Virus MT325, which infects Chlorella Pbi, encodes a Kcv channel that is similar in size (95 amino acids) to PBCV-1 Kcv. However, the predicted architecture of MT325 Kcv differs significantly from PBCV-1 $\mathrm{Kcv}$. Whereas PBCV-1 Kcv has a short amino acid cytoplasmic $\mathrm{N}$-terminus and no cytoplasmic C-terminus, MT325-Kcv is organized differently; it lacks a cytoplasmic N-terminus but has 10 amino acids at the cytoplasmic C-terminus [15]. Therefore the minimal structure and genetic variability of the $\mathrm{K}^{+}$channels encoded by the chlorella viruses provide excellent model systems to study $\mathrm{K}^{+}$channel structure-function relationships.

In this context, sequencing and annotation of another chlorella virus genome, ATCV-1, which infects Chlorella SAG 3.83 [16], revealed three ORFs (open reading frames) with the hallmarks of membrane transport proteins [17]. One ORF has the features of an aquaglyceroporin (ORF Z300R), the second of a potassium transporter (ORF Z696R) and the third of a $\mathrm{K}^{+}$ channel (ORF Z585R). The remarkable feature of this putative $\mathrm{K}^{+}$channel is that it is only 82 amino acids in size and thus 12 and 13 amino acids smaller than the other viral $\mathrm{K}^{+}$channels $[9,13,15]$. In this paper, we describe the characteristics of this putative $\mathrm{K}^{+}$channel. The results indicate that an 82 amino acid protein forms a functional $\mathrm{K}^{+}$channel. 


\section{Experimental}

\section{Expression in Saccharomyces cerevisiae cloning}

The ATCV-1 kcv gene was cloned into a yeast expression vector pYES2/CT at BamHI and XhoI sites using primer sequences: 5' primer CGGGGATCCATGTTGCTGCTTATCATA and 3' primer ATTCTCGAGCTACCACGGAAACGTGAA. pYES2/ CT (Invitrogen) carries a URA3 gene as a selectable marker for positive transformants in ura negative hosts. The exogenous gene is controlled by the GAL1 promoter and is expressed in the presence of galactose.

Both the empty vector and the vector that carries the ATCV$1 \mathrm{kcv}$ gene were transformed into a potassium uptake-deficient yeast strain SGY1528 with the lithium acetate procedure. SGY1528 has the following genotype: MATa ade2-1 can1-100 his3-11,15 leu2-3,112 trp1-1 ura3-1 trk1::HIS3 trk2::TRP1 (a gift from Dr Daniel Minor, University of California at San Francisco). Transformants were selected on low-potassium medium using the methods described by Minor et al. [18] and Chatelain et al. [19]. For the drug inhibition experiments, $\mathrm{CsCl}$ was added to the medium to produce the expected concentration before the medium was solidified with agar; $\mathrm{BaCl}_{2}$ was added to the $1 \mathrm{~cm}$ sterile paper discs at the indicated concentrations and the discs were placed on top of yeast cells spread on the agar plates. Plates were kept at $30^{\circ} \mathrm{C}$ for $72 \mathrm{~h}$ or until the yeast had reached adequate growth.

\section{Pichia pastoris transformation}

The ORF encoding the ATCV-1 kcv gene was amplified from $A T C V-1 \quad k c v$-pSGEM by the PCR (forward primer: $5^{\prime}$ CAAGGACCGAGCAGCCCCTCCTTGCTGCTTATCATACATATC-3'; reverse primer 5'-ACCACGGGGAACCAACCCTTATTACCACGGAAACGTGAAGCC-3'). The PCR fragment was subcloned into a modified $P$. pastoris expression vector pPICZ A (Invitrogen) containing a Kozak consensus sequence, $\mathrm{a} \mathrm{His}_{7}$ tag, a proteolytic site for the H3C protease and an LIC (ligation independent cloning) site on the N-terminus of the protein sequence. The construct was confirmed by DNA sequencing (Cogentech, IFOM-IEO, Milano, Italy).

$P$. pastoris cells (SMD 1163 strain) were transformed with $3 \mu \mathrm{g}$ of the PmeI linearized construct by using the Pichia Easy Comp ${ }^{\mathrm{TM}}$ Invitrogen kit as described by the manufacturer (Invitrogen). Positive colonies were selected from YPDS (10 g/ 1 bacto yeast, $20 \mathrm{~g} / 1$ bacto peptone and $20 \mathrm{~g} / 1$ dextrose) agar plates containing $50 \mu \mathrm{g} / \mathrm{ml}$ zeocin.

\section{Protein induction}

Single colonies were grown in MGYH medium $[1.34 \%(w /$ v) yeast nitrogen base, $1 \%(\mathrm{v} / \mathrm{v})$ glycerol, $4 \times 10^{-5} \%(\mathrm{w} / \mathrm{v})$ biotin and $0.004 \%$ histidine] to an attenuance $(D)$ at $600 \mathrm{~nm}$ of 4. After centrifugation at $3000 \mathrm{~g}$ for $10 \mathrm{~min}$ at $4{ }^{\circ} \mathrm{C}$, the pellet was resuspended to a $D_{600}$ of 1 in $\mathrm{MMH}$ medium $[1.34 \%$ (w/ v) yeast nitrogen base, $4 \times 10^{-5} \%(\mathrm{w} / \mathrm{v})$ biotin, $0.004 \%$ histidine and $0.5 \%(\mathrm{v} / \mathrm{v})$ methanol] and grown for $24 \mathrm{~h}$.

\section{$P$. pastoris membrane preparation}

Cells (1 g) were suspended in $22.5 \mathrm{ml}$ of breaking buffer $(50 \mathrm{mM}$ $\mathrm{NaH}_{2} \mathrm{PO}_{4}$, pH 7.4, 1 mM EDTA, 5\% glycerol and $5 \mathrm{mM}$ dithiothreitol) containing $1 \mathrm{mM}$ PMSF, $0.1 \mathrm{mg} / \mathrm{ml}$ trypsin inhibitor type II-O, $1 \mathrm{mM}$ benzamidine and $0.1 \mathrm{mM}$ Pefabloc ${ }^{\circledR}$. An equal amount $(1 \mathrm{~g})$ of ice-cold, acid washed glass beads $(0.25-0.5 \mathrm{~mm}$ diameter) was added and mixed vigorously on a vortex mixer for $20 \mathrm{~min}$ by alternating $30 \mathrm{~s}$ of vortex-mixing and $30 \mathrm{~s}$ on ice. The cell homogenate was centrifuged at $3000 \mathrm{~g}$ for $10 \mathrm{~min}$ at $4{ }^{\circ} \mathrm{C}$ to remove glass beads, unbroken cells and cell debris. The supernatant was removed and centrifuged at $30000 \mathrm{~g}$ for $45 \mathrm{~min}$ at $4{ }^{\circ} \mathrm{C}$. The resulting crude membrane pellet (microsomes) was suspended in $0.3 \mathrm{ml}$ of ice-cold breaking buffer.

\section{Immunochemistry}

For immunoblotting, SDS/PAGE-separated proteins were electro-transferred to a nitrocellulose $(0.2 \mu \mathrm{m}$; Hybond $)$ membrane, probed with anti-polyhistidine monoclonal antibody and visualized with alkaline phosphatase-coupled secondary antibody.

\section{Expression of ATCV-1 kcv and PBCV-1 kcv genes in oocytes}

$K c v$ cDNAs were cloned into a pSGEM vector (a modified version of pGEM-HE, courtesy of M. Hollmann, Max Planck Institute for Experimental Medicine, Göttingen, Germany). in vitro transcription was performed on linearized plasmids using T7 RNA polymerase (Promega) and cRNAs were injected (50 ng per oocyte) into Xenopus laevis oocytes, prepared according to standard methods [9]. Electrophysiological measurements were made 2-4 days after injection.

\section{Site-directed in vitro mutagenesis}

Point mutations were created using the QuikChange ${ }^{\circledR}$ site-directed mutagenesis kit (Stratagene, La Jolla, CA, U.S.A.) and confirmed by DNA sequencing (Cogentech, IFOM-IEO).

\section{Electrophysiological measurements}

Two-electrode voltage clamp experiments were performed using a GeneClamp 500 amplifier (Axon Instruments) and digitized at $50 \mathrm{kHz}$ with a Digidata 1200 (Axon Instruments). Data acquisition and analysis were done using the pCLAMP8 software package (Axon Instruments). Electrodes were filled with $3 \mathrm{M} \mathrm{KCl}$ and had a resistance of $0.2-0.8 \mathrm{M} \Omega$ in $50 \mathrm{mM} \mathrm{KCl}$. The oocytes were perfused at room temperature $\left(25-27^{\circ} \mathrm{C}\right)$ with a bath solution containing $50 \mathrm{mM} \mathrm{KCl}$ (or $\mathrm{RbCl}, \mathrm{CsCl}, \mathrm{NaCl}$, or $\mathrm{LiCl}$ as indicated in the Figure legend and text), $1.8 \mathrm{mM} \mathrm{CaCl}_{2}, 1 \mathrm{mM} \mathrm{MgCl}_{2}, 5 \mathrm{mM}$ Hepes, adjusted to pH 7.4 with $\mathrm{KOH}$ (or $\mathrm{RbOH}, \mathrm{CsOH}, \mathrm{NaOH}$, or $\mathrm{LiOH}$ ) at a rate of $2 \mathrm{ml} / \mathrm{min}$. Mannitol was used to adjust the osmolarity of the solution to $215 \mathrm{mosmol} / 1 . \mathrm{BaCl}_{2}$ and $\mathrm{CsCl}$ diluted from $1 \mathrm{M}$ stocks were added to the various solutions as indicated. The standard clamp protocol consisted of steps from the holding voltage of $-20 \mathrm{mV}$ to voltages in the range $+80 \mathrm{mV}$ to $-160 \mathrm{mV}$; tail currents were measured at $-80 \mathrm{mV}$. Instantaneous and steady-state currents were sampled after $10 \mathrm{~ms}$ and at the end of the voltage step (usually $600 \mathrm{~ms}$ ) respectively.

\section{Single-channel measurements by patch-clamp}

Patch pipettes were pulled from thin-walled borosilicate glass capillaries, coated with Sylgard (Dow Corning) and fire-polished to a final resistance of 8-15 $\mathrm{M} \Omega$ for single-channel experiments. Single-channel recordings were made in a cell-attached configuration. Pipette and bath solutions contained $100 \mathrm{mM} \mathrm{KCl}, 1.8 \mathrm{mM} \mathrm{CaCl}_{2}, 1 \mathrm{mM} \mathrm{MgCl}_{2}$ and $10 \mathrm{mM}$ Hepes ( $\mathrm{pH}$ adjusted to 7.4 with $\mathrm{KOH}$ ). When indicated, $100 \mathrm{mM} \mathrm{RbCl}$ was used instead of $\mathrm{KCl}$. Experiments were performed at room temperature after removal of the vitelline membrane in a hyperosmotic solution $(200 \mathrm{mM} \mathrm{NaCl})$. Currents were recorded with a Dagan 3900 amplifier; data were low-pass-filtered at $2 \mathrm{kHz}$ and digitized at a sampling rate of $10 \mathrm{kHz}$. Single-chan- 


$\begin{array}{ll}\text { A } & \\ \text { ATCV-1 } & \mathrm{KCV} \\ \text { PBCV-1 } & \mathrm{KCV} \\ & \\ & \\ \text { ATCV-1 } & \mathrm{KCV} \\ \text { PBCV-1 } & \mathrm{KCV}\end{array}$

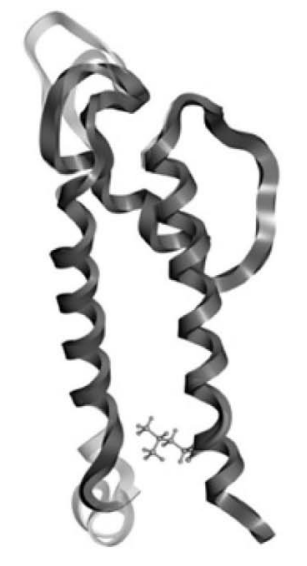

C

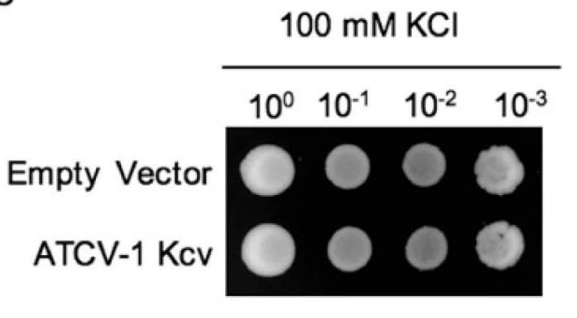

Filter

B
TM1

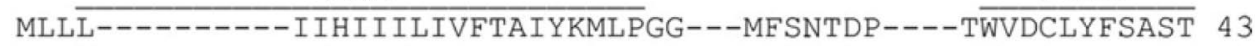
MLVFSKFLTRTEPFMIHLFILAMFVMIYKFFPGGFENNFSVANPDKKASWIDCIYFGVTT 60

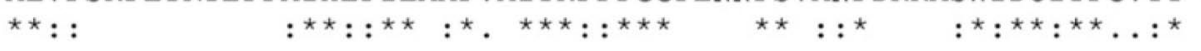
TM2 HTTVGYGDLTPKSPVAKLTATAHMLIVFAIVISGFTFP HSTVGFGDILPKTTGAKLCTIAHIVTVFFIVLTL----- 94 ${ }^{*} *^{* *}:{ }^{*}: * *: . * * *: * *:: * * * *::$

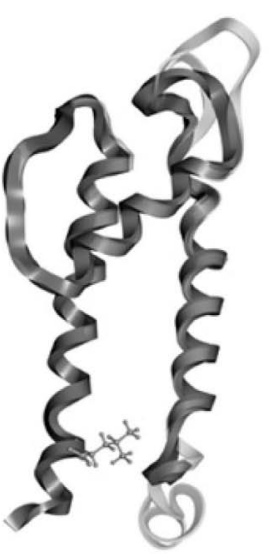

$0.5 \mathrm{mM} \mathrm{KCl}$

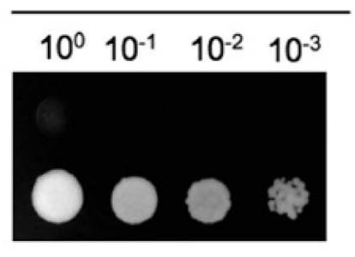

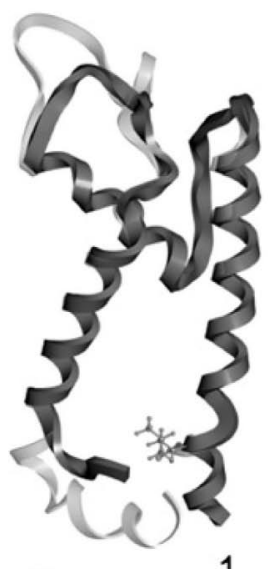

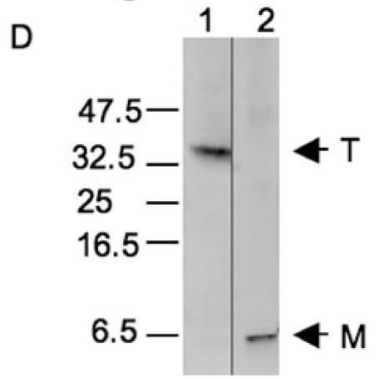

Figure 1. Sequence alignment, homology modeling and protein expression of ATCV-1 Kcv in yeast. (A) ATCV-1 Kcv sequence alignment with the sequence of the prototype chlorella virus $\mathrm{K}^{+}$channel PBCV-1 Kcv by ClustalW ( http://www.ebi.ac.uk/tools/clustalw2 ). First and second TMs (TM1 and TM2), pore helix (Pore) and selectivity filter (Filter) sequences of ATCV-1 Kcv are highlighted by horizontal lines. Assignment of these regions follows from a consensus among the prediction programs TMHMM and Phobius as well as structural data of the molecular dynamics-refined model of PBCV-1 Kcv [23]. The asterisk and colon indicate identical and conserved residues respectively. (B) Superimposition of ribbon representations of the PBCV-1 Kcv (light grey) and ATCV-1 Kcv (dark grey) structures, transverse section with two opposing monomers (left) and side view (right), visualized by MOLCAD [24] ( http://www.molcad.de ). The C-terminal residue of PBCV-1 Kcv is shown explicitly. Starting with the alignment of ATCV-1 Kcv and PBCV-1 Kcv, 3D modeling has been performed by Modeller [25] using the structure of PBCV-1 Kcv [23] as a template. PBCV-1 Kcv's C-termini have been extended by matching the corresponding KirBac1.1 helices (PDB code 1P7B), yielding a helical template structure that is long enough to superimpose ATCV-1 Kcv's C-terminus. Due to the shorter turret and N-terminal regions of ATCV-1 Kcv versus PBCV$1 \mathrm{Kcv}, \mathrm{ATCV}-1 \mathrm{Kcv}$ is overall smaller than PBCV-1 Kcv, although the C-terminal transmembrane segments of ATCV-1 Kcv are longer. The N-terminal alignment gap leads to considerable uncertainty about the correct fold, but even if the helix were extended, ATCV-1 Kcv's N-terminal TM would still be shorter. The intracellular mouth of ATCV-1 KcV, which is formed by the C-termini, is narrower in comparison with PBCV-1 Kcv. (C) Complementation of a $\Delta t r k 1, \Delta t r k 2$ mutant of $S$. cerevisiae with empty vector (control) and ATCV-1 Kcv. The transformed yeast was grown at two $\mathrm{K}^{+}$ concentrations: $100 \mathrm{mM} \mathrm{KCl}$ (permissive) and $0.5 \mathrm{mM} \mathrm{KCl}$ (selective). Numbers in a row indicate subsequent dilutions of the cell culture that were plated to avoid artifactual growth. (D) SDS/PAGE and Western-blot analysis of microsomes from P. pastoris expressing recombinant ATCV-1 Kcv fused to a His ${ }_{7}$ tag identified with an anti-His tag commercial antibody. Lane 1, unboiled sample; lane 2, sample boiled for 3 min at $100^{\circ} \mathrm{C}$. T and $\mathrm{M}$ indicate the presumed tetrameric and monomeric states of the protein. Numbers on the left are molecular mass markers (in $\mathrm{kDa}$ ).

nel analysis was done using pCLAMP 9 (Axon Instruments) with the threshold-based algorithm.

\section{Ion permeability}

Permeability ratios $\left(P_{\mathrm{X}} / P_{\mathrm{K}}\right)$ were calculated according to the equation $\Delta E_{\mathrm{rev}}=E_{\mathrm{revX}}-E_{\mathrm{rev}, \mathrm{K}}=R T / z F \ln P_{\mathrm{X}}[\mathrm{X}]_{\mathrm{O}} / P_{\mathrm{K}}[\mathrm{K}]_{\mathrm{O}^{\prime}}$, where $E_{\text {rev }}$ is the value in $\mathrm{mV}$ of the current reversal potential measured in the presence of the different univalent cations in the external solution (either $\mathrm{X}^{+}$or $\mathrm{K}^{+}$); $[\mathrm{X}]_{\mathrm{O}}$ and $[\mathrm{K}]_{\mathrm{O}}$ are the cation concentrations in the external solution; and $R, T, z$ and $F$ have their usual thermodynamic meanings.

\section{Results and Discussion}

Virus ATCV-1 codes for a channel protein with 82 amino acids

The chlorella virus ATCV-1 genome was recently sequenced and annotated [17]. Among the 860 ORFs, one (ORF Z585R) had all the hallmarks of a $\mathrm{K}^{+}$channel. The derived amino acid sequence of Z585R, termed ATCV-1 Kcv, is compared with the sequence of the prototype viral $\mathrm{K}^{+}$channel, PBCV-1 Kcv in Figure $1(\mathrm{~A})$. The ATCV-1 Kcv sequence is only 82 amino acids in size, 12 residues smaller than PBCV-1 Kcv. In spite of ATCV$1 \mathrm{Kcv}^{\prime} \mathrm{s}$ small size, the protein has the essential features of a 

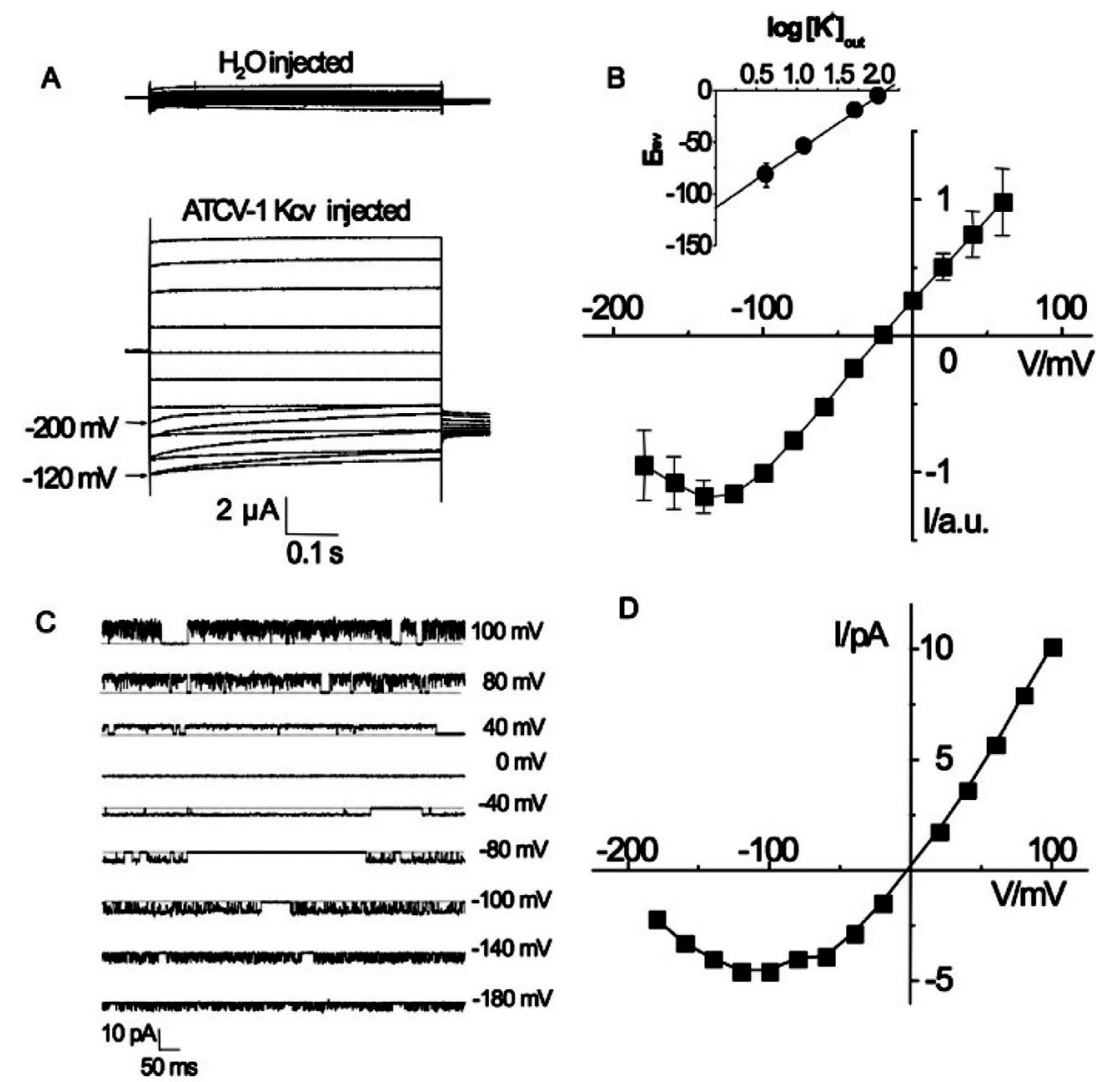

Figure 2. Properties of ATCV-1 Kcv currents at the macroscopic and single channel level. (A) Exemplary macroscopic current traces recorded by a two-electrode voltage clamp from an oocyte injected with water for control and from an oocyte injected with cRNA of ATCV-1 Kcv. Clamp protocol: holding potential $-20 \mathrm{mV}$, steps from 60 to $-200 \mathrm{mV}$. The external solution contained $50 \mathrm{mM} \mathrm{KCl}$. Arrows indicate instantaneous current level at -120 and $-200 \mathrm{mV}$ to show reduction at extreme negative voltages. (B) The $I / V$ relationship of instantaneous (measured $3 \mathrm{~ms}$ after the voltage step) currents shown in (A). Current values are expressed in arbitrary units (a.u.) and are the means for $n \geq 5$ different oocytes \pm S.E.M. (error bars smaller than the symbol are not visible) normalized to the current value recorded at $-100 \mathrm{mV}$. The mean values ( $n \geq 3 \pm$ S.E.M.) of reversal potential $\mathrm{E}_{\text {rev }}$ plotted as a function of $\log \left[\mathrm{K}^{+}\right]_{\text {out }}$ are shown in the inset of $(\mathbf{B}) .\left[\mathrm{K}^{+}\right]_{\text {out }}$ was $6,10,50$, and $100 \mathrm{mM}$ and $\left[\mathrm{K}^{+}\right]_{\text {in }}$ was assumed to be $108.6 \mathrm{mM}$ [26]. The slope of the linear relationship is $53.9 \mathrm{mV}$. (C) Exemplary single channel fluctuations recorded at different voltages in cell-attach configuration from an oocyte expressing ATCV-1 Kcv. The pipette solution contained $100 \mathrm{mM} \mathrm{KCl}$. The dotted line marks the closed channel level of the current. (D) Open state $I / V$ relationship of the single channel shown in (C).

$\mathrm{K}^{+}$channel. Structural prediction programs TMHMM (http:// www.cbs.dtu.dk/services/TMHMM ) and Phobius (http:// phobius.cbr.su.se ) suggest two TMs, TM1 and TM2, and a pore helix (Phobius) preceding the filter region; it has a canonical selectivity filter sequence (TTVGYGD) and the aromatic couple, YF, in the pore helix. The two proteins have considerable sequence identity and similarity (Figure 1A) but presumably differ in structure as shown by the superimposed structural models in Figure 1(B). ATCV-1 Kcv lacks the 'slide helix' at the N-terminus (amino acids 1-14 in PBCV-1 Kcv) and most of the external loop connecting TM1 to the pore helix, the 'tur-

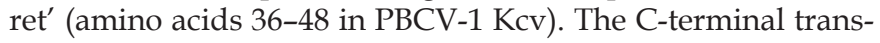
membrane segments, TM2, of ATCV-1 Kcv are longer and the intracellular mouth of this channel is probably narrower in comparison with PBCV-1 Kcv. The finding that ATCV-1 Kcv lacks the slide helix is of particular interest since this domain is essential for PBCV-1 KcV activity [11].

\section{ATCV-1 Kcv forms a functional $\mathrm{K}^{+}$channel}

The first indication that ATCV-1 Kcv forms a functional $\mathrm{K}^{+}$ channel was obtained by complementation of a $S$. cerevisiae $\Delta t r k 1, \Delta t r k 2$ mutant that lacks endogenous $\mathrm{K}^{+}$uptake systems $[18,19]$. Expression of ATCV-1 Kcv protein in the mutant rescued yeast growth in low $\mathrm{K}^{+}(0.5 \mathrm{mM})$, whereas yeast trans- formed with the empty vector only grew in high $\mathrm{K}^{+}(100 \mathrm{mM})$ (Figure 1C). These results indicate that ATCV-1 Kcv forms a functional $\mathrm{K}^{+}$channel presumably at the yeast plasma membrane. Growth of the ATCV-1 Kcv expressing yeast was inhibited by $\mathrm{Ba}^{2+}$ and $\mathrm{Cs}^{+}$, two known $\mathrm{K}^{+}$channel blockers (Figure $4 \mathrm{~A}$ and Supplementary Figure S1A).

\section{ATCV-1 Kcv forms a stable tetramer}

Since functional $\mathrm{K}^{+}$channels are tetrameric [20], the oligomeric state of ATCV-1 Kcv protein was examined. The channel was expressed in the yeast $P$. pastoris with an N-terminal His tag [12]. The microsomal proteins were analyzed by SDS/PAGE; one band, with an apparent molecular mass of $32.5 \mathrm{kDa}$, was detected by anti-histidine antibody (Figure 1D, lane 1). The observed mass is roughly four times that of the monomer $(6.5 \mathrm{kDa})$ obtained after heating the sample at $100{ }^{\circ} \mathrm{C}$ for $3 \mathrm{~min}$ (Figure 1D, lane 2); this result indicates that ATCV-1 Kcv can form a stable tetramer.

\section{ATCV-1 Kcv has characteristic electrical properties}

ATCV-1 Kcv was expressed in Xenopus oocytes and subjected to electrophysiological investigation by the two-electrode voltage clamp procedure. Macroscopic currents occurred (Figure 2A) that clearly differ in amplitude and kinetics from the en- 

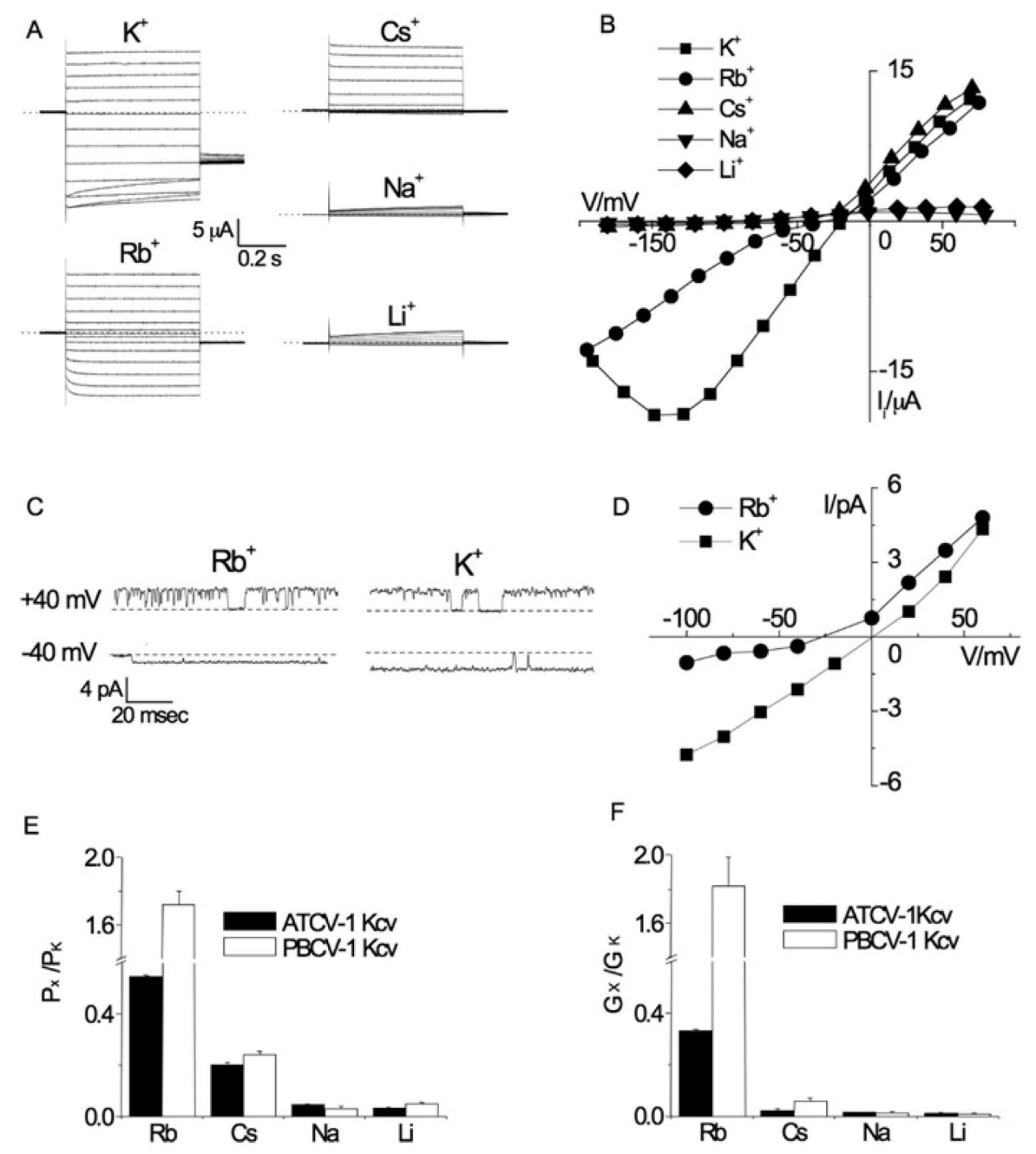

Figure 3. Permeability and conductance of ATCV-1 Kcv to different univalent cations. (A) Currents recorded by a two-electrode voltage clamp experiment with $50 \mathrm{mM} \mathrm{KCl}, \mathrm{RbCl}, \mathrm{CsCl}, \mathrm{NaCl}$, and $\mathrm{LiCl}$ in the external solution. The dotted line indicates zero current. (B) The $I / V$ relations of the currents reported in (A). The plotted values are of instantaneous current $\left(I_{i}\right)$, measured $3 \mathrm{~ms}$ after the voltage step. (C) Comparison of single channel recordings of ATCV-1 Kcv measured in cell-attach experiment at +40 and $-40 \mathrm{mV}$ with either $100 \mathrm{mM} \mathrm{RbCl}$ or $\mathrm{KCl}$ in the pipette solution. The dotted line marks the closed channel level of the current. (D) Corresponding $I / V$ relation of the experiment from which traces at $+/-40 \mathrm{mV}$ are displayed in $(\mathbf{C})$. Note the negative shift of the reversal potential in the presence of $\mathrm{Rb}^{+}$. (E) Permeability ratios, $P_{\mathrm{X}} / P_{\mathrm{K}^{\prime}}$ calculated from mean reversal potentials of macroscopic currents obtained from $n \geq 5$ oocytes (Table 1). (F) Conductance ratios, $G_{X} / G_{K}$, calculated from slope conductance of macroscopic relationships in the linear range from -50 to $-100 \mathrm{mV}$. Mean values are from $n=4$ oocytes (Table 1 ).

dogenous currents (water-injected oocyte). The ATCV-1 Kcvinduced currents have features typical of other chlorella virus Kcv channels [9,13-15]. The voltage clamp protocol (holding potential $-20 \mathrm{mV}$, steps from 60 to $-200 \mathrm{mV}$ ) evoked large instantaneous currents, which resulted in the current-voltage $(I / V)$ relationship shown in Figure 2(B). The channel conductance is approximately linear between $+/-80 \mathrm{mV}$ but shows a pronounced negative slope at extreme negative voltages. Figure 2(A) shows, as an example, that the instantaneous current level recorded at $-200 \mathrm{mV}$ is smaller than that at $-120 \mathrm{mV}$. Macro currents of Figure 2(A) also show a slow kinetic component at negative potentials that is interpreted as an inactivation of ATCV-1 Kcv conductance.

\section{ATCV-1 Kcv is $\mathrm{K}^{+}$selective}

ATCV-1 Kcv channel currents were recorded in bath solutions with different ionic compositions to examine its selective properties. An increase of $\mathrm{KCl}$ concentration from 6 to $100 \mathrm{mM}$ resulted in a progressive negative shift of the current reversal voltage. The inset in Figure 2(B) shows the semi-logarithmic relationship between the measured current reversal potential and the external $\mathrm{K}^{+}$concentration. Linear regression analysis resulted in a straight line with a slope of $53.9 \pm 1.4 \mathrm{mV}(n \geq 3)$. This value is close to the theoretical value of $59.2 \mathrm{mV}$ calculated with the Nernst equation [21] and indicates that ATCV-1 $\mathrm{Kcv}$ is a $\mathrm{K}^{+}$channel.

\section{Single-channel properties}

To examine the single-channel activity that underlies the ATCV-1 Kcv conductance, we measured the current in the plasma membrane of oocytes by the patch clamp method in cell-attach configuration. A typical example of single-channel fluctuations monitored in oocytes expressing the viral protein is shown in Figure 2(C). The $I / V$ relationship of the unitary conductance (Figure 2D) has a pronounced outward rectifying shape and closely resembles that of the macro currents reported in Figure 2(B). The nonlinearity of the single channel I/ $V$ curve is a typical feature of this as well as of other Kcv chan- 
nels and is due to a voltage-dependent reduction in the apparent channel conductance. At voltages more negative than $-50 \mathrm{mV}$, the $I / V$ curve progressively bends because the unitary currents become smaller even though the driving force is increasing. The reason for this voltage-dependent decrease in unitary conductance was not analyzed further; however, since the lifetime of the channel openings becomes shorter with negative voltages it is likely due to a fast gating mechanism. Note that the full openings are not recorded at very negative voltages. In the linear range $\pm 50 \mathrm{mV}$, the estimated single channel conductance was $80 \mathrm{pS}$. This value is similar to that of PBCV$1 \mathrm{Kcv}$, which, under the same ionic conditions $(100 \mathrm{mM}$ symmetric $\mathrm{K}^{+}$), has a unitary conductance of approx. 100 pS ([12] and A. Abenavoli, unpublished work).

In summary, the membrane conductance generated by ATCV-1 Kcv is due to the activity of a canonical ion channel that displays a characteristic voltage-dependent decrease in the unitary channel conductance. ATCV-1 Kcv thus resembles PBCV$1 \mathrm{Kcv}$ that also exhibits a voltage-dependent single-channel I/ $V$. This result indicates that the structural elements that underlie the gating mechanism are shared by both channel proteins.

\section{Permeability to univalent cations}

To study the permeability of ATCV-1 Kcv, we performed twoelectrode voltage clamp experiments with different univalent cations in the external solution. Replacing $50 \mathrm{mM} \mathrm{K}^{+}$with $\mathrm{Rb}^{+}$, $\mathrm{Cs}^{+}, \mathrm{Na}^{+}$or $\mathrm{Li}^{+}$resulted in the macroscopic currents shown in Figure 3(A) from which the corresponding $I / V$ relations were produced (Figure $3 \mathrm{~B}$ ). Only $\mathrm{Rb}^{+}$permeates the channel among the tested cations, as shown by the presence of an inward current. Rubidium induced a negative shift in the current reversal potential, $E_{\text {rev }}$ of $16 \mathrm{mV}$ (more clearly visible in Figure 5A: $E_{\text {rev }}$ $\mathrm{K}^{+}=-20 \pm 1.08 \mathrm{mV}$ and $\left.E_{\mathrm{rev}} \mathrm{Rb}^{+}=-36.2 \pm 0.86 \mathrm{mV}, n=7\right)$. A qualitatively similar result was obtained when the permeability to rubidium was tested at the single channel level. Figure 3(C) shows examples of single-channel currents of ATCV-1 Kcv recorded in a cell-attach configuration with $100 \mathrm{mM} \mathrm{KCl}$ or $\mathrm{RbCl}$ in the pipette. Replacing external $\mathrm{K}^{+}$with $\mathrm{Rb}^{+}$resulted in a reduction in inward current amplitude and a negative shift of the reversal potential (Figure 3D). These results indicate that $\mathrm{Rb}^{+}$has a lower permeability than $\mathrm{K}^{+}$and confirm the results obtained with macro currents. Taking the constant field model as a basis for explaining selectivity [21], we have used macroscopic current $E_{\text {rev }}$ to estimate the permeability ratios reported in Figure 3(E) $\left(P_{\mathrm{X}} / P_{\mathrm{K}^{\prime}}\right.$, where $\mathbf{X}$ is the tested cation) by using a simplified version of the Goldman equation (see the Experimental section). ATCV-1 Kcv is compared with PBCV-1 Kcv to highlight its peculiar behavior; ATCV-1 Kcv is indeed the only Kcv channel found so far with a $P_{\mathrm{Rb}} / P_{\mathrm{K}}<1$ [13]. The permeability sequence of ATCV- $1 \mathrm{KcV}$ is $\mathrm{K}^{+}>\mathrm{Rb}^{+}>\mathrm{Cs}^{+}>>\mathrm{Na}^{+} \approx \mathrm{Li}^{+}$, whereas that of PBCV-1 Kcv is $\mathrm{Rb}^{+}>\mathrm{K}^{+}>\mathrm{Cs}^{+}>>\mathrm{Li}^{+} \geq \mathrm{Na}^{+}$([13] and Table 1). A closer view of the currents recorded with different cations indicates that the cation composition of the medium affects other aspects of the $I / V$ relations of the channel in addition to the reversal potential. Replacement of $\mathrm{K}^{+}$with $\mathrm{Na}^{+}$or $\mathrm{Li}^{+}$not only reduces the inward current of the ATCV-1 $\mathrm{Kcv}$ generated conductance but also abolishes its outward current. This result is consistent with a blocking effect of external $\mathrm{Na}^{+}$and $\mathrm{Li}^{+}$on the outward $\mathrm{K}^{+}$current. A reasonable explanation for this effect is that $\mathrm{Na}^{+}$or $\mathrm{Li}^{+}$enters the filter in the absence of $\mathrm{K}^{+}$and that this entry results in a destabilization of the filter geometry [20]. A similar effect by $\mathrm{Na}^{+}$, but not $\mathrm{Li}^{+}$, was previously reported for the prototype PBCV-1 Kcv channel [9]. The present data indicate that $\mathrm{Li}^{+}$behaves like $\mathrm{Na}^{+}$in
Table 1. Permeability and conductance of wild-type and mutant channels to different univalent cations. All cations were $50 \mathrm{mM}$ as chloride salts. $P_{\mathrm{X}} / P_{\mathrm{K}}{ }^{+}$is the permeability of the ion $\mathrm{X}^{+}$relative to $\mathrm{K}^{+}$, calculated from current reversal potentials (see the Experimental section). $G_{X} /$ $\mathrm{G}_{\mathrm{K}}{ }^{+}$is the ratio of chord conductances calculated at $-100 \mathrm{mV}$. Values are the means \pm S.E.M.; $n=$ number of oocytes.

\begin{tabular}{|c|c|c|c|c|c|c|c|c|}
\hline & \multicolumn{4}{|l|}{ ATCV-1 } & \multicolumn{4}{|l|}{ PBCV-1 } \\
\hline & $P_{\mathrm{X}} / P_{\mathrm{K}}^{+}$ & $n$ & $G_{\chi} / G_{K}^{+}$ & $n$ & $P_{\mathrm{X}} / P_{\mathrm{K}}^{+}$ & $n$ & $G_{\mathrm{X}} / G_{\mathrm{K}}^{+}$ & $n$ \\
\hline$\overline{\mathrm{K}^{+}}$ & 1 & - & 1 & - & 1 & - & 1 & $\overline{-}$ \\
\hline $\mathrm{Rb}^{+}$ & $0.54 \pm 0.01$ & 7 & $0.33 \pm 0.01$ & 4 & $1.72 \pm 0.08$ & 5 & $1.82 \pm 0.17$ & 4 \\
\hline $\mathrm{Cs}^{+}$ & $0.20 \pm 0.01$ & 5 & $0.02 \pm 0.01$ & 4 & $0.24 \pm 0.01$ & 8 & $0.06 \pm 0.01$ & 4 \\
\hline $\mathrm{Na}^{+}$ & $0.04 \pm 0.01$ & 10 & $<0.001$ & 4 & $0.03 \pm 0.01$ & 5 & $<0.001$ & 4 \\
\hline \multirow[t]{3}{*}{$\mathrm{Li}^{+}$} & $0.03 \pm 0.01$ & 9 & $<0.001$ & 4 & $0.05 \pm 0.01$ & 10 & $<0.01$ & 4 \\
\hline & \multicolumn{4}{|c|}{ ATCV-1 Y49F } & \multicolumn{4}{|c|}{ PBCV-1 F66Y } \\
\hline & $P_{X} / P_{K}^{+}$ & $n$ & $G_{X} / G_{K}^{+}$ & $n$ & $P_{X} / P_{K}^{+}$ & $n$ & $G_{X} / G_{K}^{+}$ & $n$ \\
\hline $\mathrm{K}^{+}$ & 1 & - & 1 & - & 1 & - & 1 & - \\
\hline $\mathrm{Rb}^{+}$ & $0.76 \pm 0.02$ & 8 & $2.80 \pm 0.45$ & 4 & $1.26 \pm 0.02$ & 10 & $1.53 \pm 0.13$ & 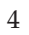 \\
\hline $\mathrm{Cs}^{+}$ & $0.03 \pm 0.01$ & 7 & $<0.01$ & 4 & $0.13 \pm 0.01$ & 8 & $0.03 \pm 0.01$ & 4 \\
\hline $\mathrm{Na}^{+}$ & $0.04 \pm 0.01$ & 5 & $<0.01$ & 4 & $0.04 \pm 0.01$ & 6 & $<0.01$ & 4 \\
\hline $\mathrm{Li}^{+}$ & $0.02 \pm 0.01$ & 5 & $<0.01$ & 4 & $0.05 \pm 0.01$ & 7 & $<0.01$ & 4 \\
\hline
\end{tabular}

the ATCV-1 Kcv channel, meaning that structural differences between the two channels could allow the small $\mathrm{Li}^{+}$ion to enter the pore. In contrast, $\mathrm{Cs}^{+}$does not have the same effect on the outward $\mathrm{K}^{+}$currents, which resemble the control condition (with external $\mathrm{K}^{+}$).

The aforementioned results imply that the cations interact with the channel protein. Hence permeation through $\mathrm{Kcv}$ channels is more complex than predicted by constant field theory. The nonlinearity of the $I_{\mathrm{i}} / V$ relations, i.e. in $\mathrm{Rb}^{+}$and $\mathrm{K}^{+}$, furthermore implies that the permeability ratios could be voltage dependent, as shown by Eisenman and Horn [22]. For this reason the $E_{\text {rev }}$ value alone is not sufficient to provide an absolute measure of $\mathrm{Kcv}$ channel permeability. We also estimated the conductance of the channel for different ions away from equilibrium [22]. This relative conductance, $G_{X} / G_{K^{\prime}}$ provides additional information on the selectivity of the channels beyond the constant field theory.

The overall inward current in the presence of $\mathrm{Rb}^{+}$is smaller than in $\mathrm{K}^{+}$, as expected from the lower permeability of the channel in $\mathrm{Rb}^{+}$. This results in a low conductance ratio (Figure 3F and Table 1: $G_{\mathrm{Rb}} / G_{\mathrm{K}}=0.3$, conductance estimated in the linear portion of the $I / V$ relation) and again confirms a difference in behavior between ATCV-1 Kcv and PBCV-1 KcV, which has a conductance ratio value largely higher than 1 (Table 1: $G_{\mathrm{Rb}} /$ $G_{K}=1.8$ ). Finally it has to be mentioned that the kinetics of the channel change as a consequence of the transported substrate. While the inward current in $\mathrm{K}^{+}$has a slow inactivating component, the current activates in a slow manner when $\mathrm{Rb}^{+}$is present in the medium. This kinetic effect was not analyzed further in the present study.

\section{ATCV-1 Kcv is blocked by conventional $\mathrm{K}^{+}$channel blockers}

As mentioned previously, the yeast complementation experiments indicate that ATCV-1 Kcv is sensitive to the two $\mathrm{K}^{+}$channel blockers $\mathrm{Ba}^{2+}$ (Figure $4 \mathrm{~A}$ ) and $\mathrm{Cs}^{+}$(Supplementary Figure S1A). Figure 4(A) shows that, in selective conditions $(0.5 \mathrm{mM} \mathrm{KCl})$, growth of yeast expressing ATCV-1 Kcv is strongly reduced by $1 \mathrm{mM} \mathrm{Ba}{ }^{2+}$. To confirm and further study the $\mathrm{Ba}^{2+}$ block, ATCV-1 KcV macro currents were recorded in oocytes with and without $\mathrm{Ba}^{2+}$ in the external solution. Figure $4(\mathrm{~B})$ shows the current response of an oocyte expressing ATCV-1 Kcv before and after addition of $1 \mathrm{mM} \mathrm{Ba}^{2+}$ to an ex- 
A

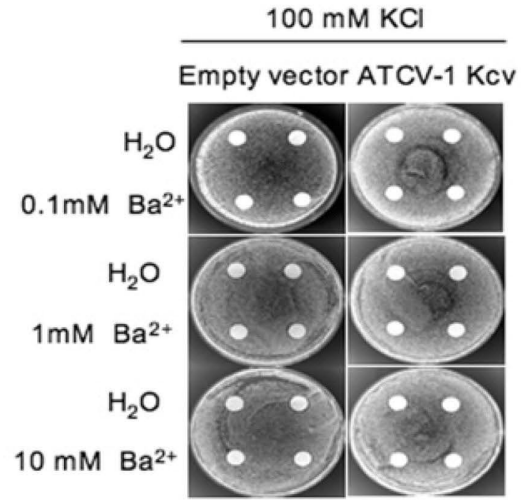

$0.5 \mathrm{mM} \mathrm{KCl}$

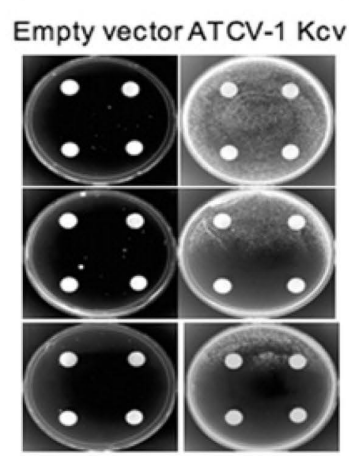

B

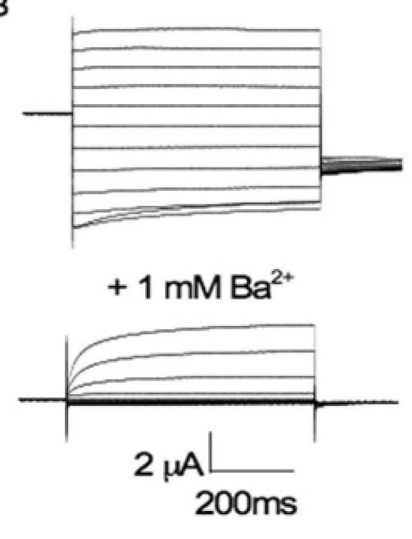

D

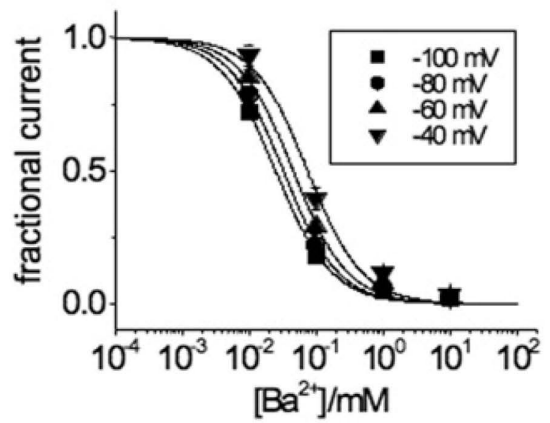

C

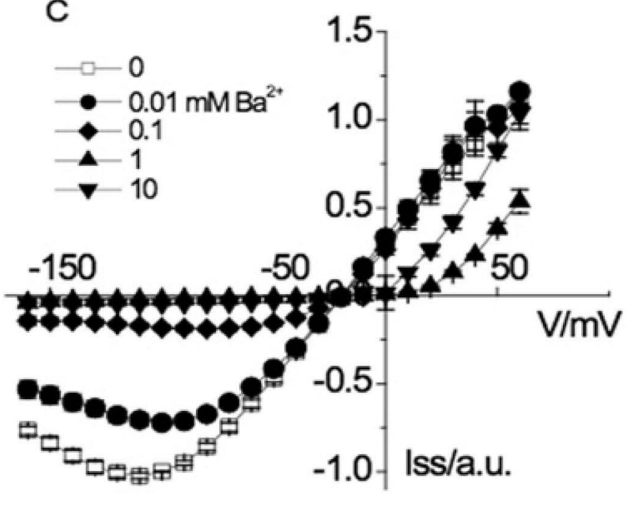

$E$

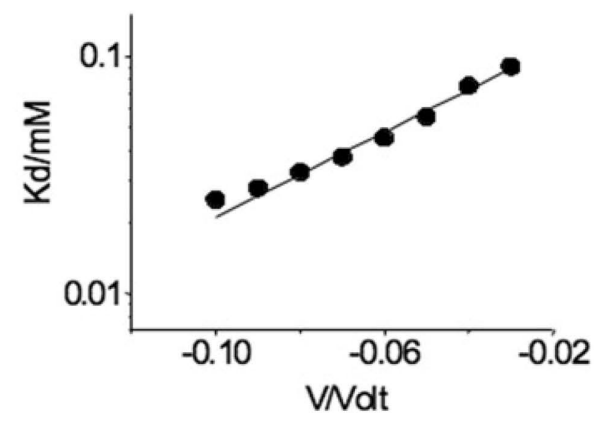

Figure 4. ATCV-1 Kcv is blocked by external $\mathrm{Ba}^{2+}$. (A) Complementation assay performed on a $\Delta$ trk1, $\Delta$ trk2 yeast mutant transformed with empty vector (control) and ATCV-1 Kcv. Yeast growth was tested by adding various $\mathrm{Ba}^{2+}$ concentrations (water for control) to the paper discs in the plates. (B) Effect of $1 \mathrm{mM} \mathrm{Ba}^{2+}$ on ATCV-1 Kcv currents recorded in $50 \mathrm{mM} \mathrm{K}^{+}$. (C) The $I / V$ relationship of ATCV-1 Kcv currents recorded at different external $\mathrm{Ba}^{2+}$ concentrations. Steady-state current values $\left(I_{\mathrm{ss}^{\prime}}\right.$ measured at the end of the voltage pulse) are expressed in arbitrary units (a.u.) because normalization was performed at the current value at $-100 \mathrm{mV}$ to allow comparison of different oocytes $(n=9)$. When not visible, error bars ( \pm S.E.M.) are smaller than symbols. (D) The dose-response curve, obtained by plotting the fractional current, $I_{\mathrm{f}}$, as a function of $\left[\mathrm{Ba}^{2+}\right]_{\text {out }}{ }^{*}$ Curves were fitted with the Hill equation (see text) at fixed $n=1 . K_{\mathrm{d}}=24,32,45$, and $75 \mu \mathrm{M}$ at $-100,-80,-60$, and $-40 \mathrm{mV}$ respectively. (E) Semilogarithmic plot of the $K_{d}$ against the membrane potential. $K_{d}$ was obtained from the dose-response curve obtained from data plotted in (C), extending the analysis to potentials not shown in (D). Lines are drawn by a least-square fitting. $K_{\mathrm{d}}$ decreased e-fold for $120 \mathrm{mV}$ hyperpolarization.

ternal solution containing $50 \mathrm{mM} \mathrm{K}$. Barium produces a voltage-dependent block of the ATCV-1 Kcv conductance. It abolishes the inward current and also slightly affects the outward current. The overall effect of $\mathrm{Ba}^{2+}$ is summarized in the mean $I / V$ curves obtained with four different $\mathrm{Ba}^{2+}$ concentrations, $0.01,0.1,1$ and $10 \mathrm{mM}$ (Figure $4 \mathrm{C}$ ); ATCV-1 Kcv is partially blocked by sub-millimolar concentrations of $\mathrm{Ba}^{2+}$. The doseresponse relationship of the $\mathrm{Ba}^{2+}$ block was obtained at different test potentials and plotted in Figure 4(D). The plotted values of fractional current, $I_{\mathrm{f}}$, could be fitted by the Hill equation as follows:

$$
I_{\mathrm{f}}=K_{\mathrm{d}}^{n} /\left(K_{\mathrm{d}}^{n}+\left[\mathrm{Ba}^{2+}\right]^{n}\right)
$$

where $K_{\mathrm{d}}$ is the concentration of $\mathrm{Ba}^{2+}$ for half inhibition and $n$ is the Hill coefficient. Since the best fit of $n$ was between 1.03 and 1.07, we fixed $n$ at 1 . The resulting $K_{\mathrm{d}}$ for $\mathrm{Ba}^{2+}$ changed with voltage and was $31,40,55$, and $85 \mu \mathrm{M}$ at $-100,-80,-60$, and -40 $\mathrm{mV}$ respectively. Owing to the voltage-dependent nature of the block, the apparent $K_{d}$ obtained from the dose-response curves varies in a linear fashion with voltage when plotted in a semilogarithmic scale (Figure $4 \mathrm{E}$ ). The extrapolated value of $K_{\mathrm{d}}$ at 0 $\mathrm{mV}$ was $0.16 \mathrm{mM}$ and decreased e-fold by $120 \mathrm{mV}$ hyperpolar- 
A

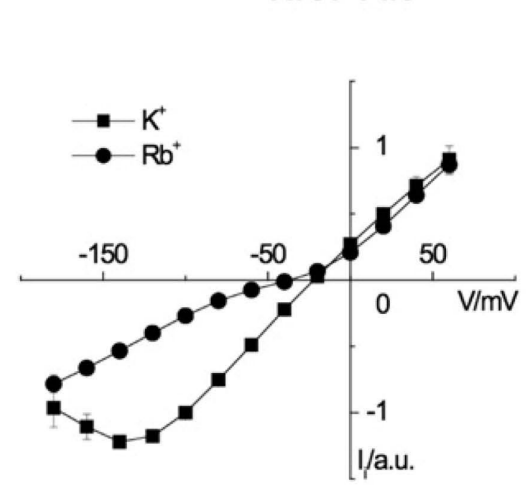

C

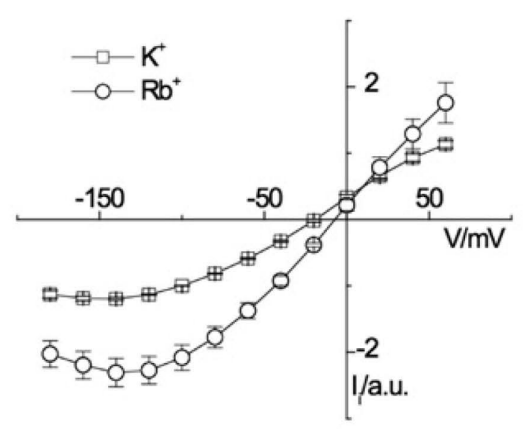

B ATCV-1 Y49F

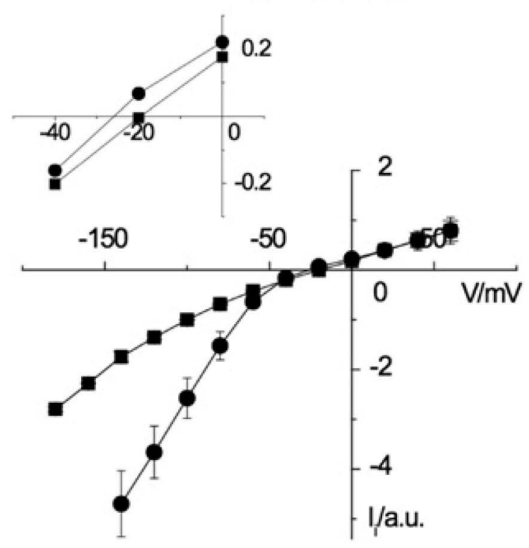

D

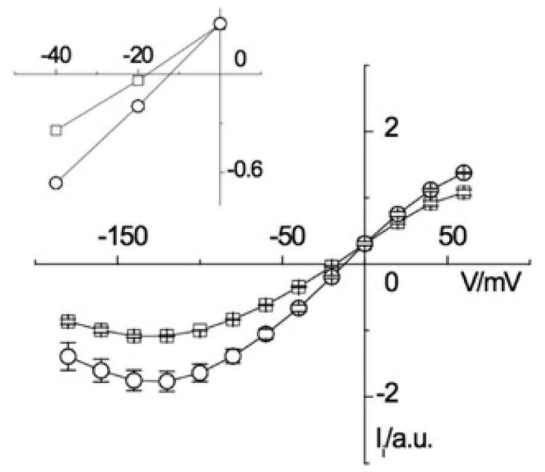

Figure 5. Effect of a mutation in the selectivity filter on conductance and permeability to rubidium. (A) ATCV-1 Kcv sequence GYG was changed to GFG in the Y49F mutant displayed in (B). (C) PBCV-1 Kcv sequence GFG was changed to GYG in the F66Y mutant displayed in (D). Measurements performed in oocytes by a two-electrode voltage clamp, applying the standard voltage protocol (see the Experimental section) and in the presence of $50 \mathrm{mM}$ external $\mathrm{KCl}$ (squares) or $\mathrm{RbCl}$ (circles). The plotted values are of instantaneous current $\left(I_{\mathrm{i}}\right)$, measured 3 ms after the voltage step. Each set of data is normalized to the value of the current at $-100 \mathrm{mV}$ to include measurements from different oocytes and is expressed in arbitrary units (a.u.). Mean values \pm S.E.M. ( $n=7$ for ATCV- 1 wild-type, $n=8$ for ATCV-1 Y49F, $n=5$ for PBCV- 1 wild-type and $n=10$ for F66Y). (A) The Figure includes a set of data already displayed in Figure 3(B). Insets of (B, D) show enlargement of the $I / V$ relationship to allow better appreciation of shifts in current reversal potentials induced by $\mathrm{Rb}^{+}:-7 \mathrm{mV}$ for ATCV-1 Kcv Y49F $\left(E_{\mathrm{rev}} \mathrm{K}^{+}=-21.52 \pm 1.13 \mathrm{mV} ; E_{\mathrm{rev}} \mathrm{Rb}=-28.13 \pm 1.11 \mathrm{mV}\right)$ and $+6 \mathrm{mV}$ for PBCV-1 Kcv F66Y $\left(E_{\mathrm{rev}} \mathrm{K}^{+}=-19.97 \pm 0.31 \mathrm{mV} ; E_{\mathrm{rev}} \mathrm{Rb}^{+}=-14.07 \pm 0.39 \mathrm{mV}\right)$.

ization, confirming that the $\mathrm{Ba}^{2+}$ block is facilitated by hyperpolarization. Collectively these data show that the smaller version of a Kcv-type channel behaves similarly to its larger orthologues. Other Kcv channels are also blocked by $\mathrm{Ba}^{2+}$ in a voltage-dependent manner with $K_{d}$ values in the range of tens of micrometers ([9]; A. Moroni, unpublished work).

The same procedure was used to examine $\mathrm{Cs}^{+}$-sensitivity of the ATCV-1 Kcv channel. Addition of micromolar levels of $\mathrm{Cs}^{+}$inhibits yeast growth when expressing the ATCV-1 Kcv channel (Supplementary Figure S1A). The electrophysiology data in Supplementary Figures S1(B)-S1(E) can be summarized as follows: ATCV-1 Kcv is inhibited by sub-millimolar concentrations of $\mathrm{Cs}^{+}$in a strong voltage-dependent manner. The $K_{\mathrm{d}}$ value is strongly voltage-dependent and decreases efold for $31 \mathrm{mV}$ hyperpolarization.

\section{Structural basis for the difference in $\mathrm{Rb}^{+}$selectivity}

The macroscopic and microscopic $I / V$ data in Figure 3 reveal that the ATCV-1 Kcv-generated channel is better at conducting $\mathrm{K}^{+}$than $\mathrm{Rb}^{+}$. This behavior is unusual for Kcv-type channels since all Kcv-like channels characterized to date [13] conduct $\mathrm{Rb}^{+}$better than $\mathrm{K}^{+}$. In search of a structural explanation for this difference we noted that ATCV-1 Kcv has a tyrosine in the conserved selectivity sequence of the filter (GYG), whereas PBCV-1 Kcv has a phenylalanine (GFG) (Figure 1A). To determine whether this substitution in the filter region is responsible for the difference in $\mathrm{Rb}^{+}$conductance and permeability, we prepared mutant channels in which we exchanged the two residues, i.e. ATCV-1 Kcv Y49F and PBCV-1 Kcv F66Y.

Both mutants were functional in oocytes and produced macrocurrents that were tested for $\mathrm{K}^{+}$selectivity; both exhibited Nernstian behavior when tested in buffers with different $\mathrm{KCl}$ concentrations (see Supplementary Figure S2). The I/ V relationships obtained from wild-type and mutant channels in the presence of $\mathrm{K}^{+}$and $\mathrm{Rb}^{+}$are presented in Figure 5 (mean data for wild-type ATCV-1 Kcv of Figure 5A include the data set of Figure $3 \mathrm{~B})$. For the aforementioned reasons we again used both the shift of $E_{\text {rev }}\left(\Delta E_{\text {rev }}=E_{\text {rev Rb }}-E_{\text {rev K }}\right)$ and the ratio in conductance $\left(G_{\mathrm{Rb}} / G_{\mathrm{K}}\right)$ as parameters to estimate the selectivity of the channel for $\mathrm{K}^{+}$over $\mathrm{Rb}^{+}$. In the case of ATCV-1 Kcv, the $\mathrm{Y} 49 \mathrm{~F}$ mutation results in a dramatic increase in $\mathrm{Rb}^{+}$conductance and a small negative $\Delta E_{\mathrm{rev}}$ of $-7 \mathrm{mV}$ (inset of Figure $2 \mathrm{~B}$ shows an enlargement of the currents at $E_{\text {rev }} \mathrm{K}^{+}=-21.52 \pm$ $\left.1.13 \mathrm{mV}, n=5 ; \mathrm{Rb}^{+}=-28.13 \pm 1.11 \mathrm{mV}, n=4\right)$. The conductance ratio, $G_{\mathrm{Rb}} / G_{\mathrm{K}}$, increases from 0.33 in the wild-type to 2.8 in the mutant (Table 1 ), while the permeability ratio, $P_{\mathrm{Rb}+} / P_{\mathrm{K}+}$, estimated from the shift in $E_{\mathrm{rev}}$ is increased from $0.54 \pm 0.01$ in the 
wild-type to $0.76 \pm 0.02$ in the mutant (Table 1). These results imply that phenylalanine and tyrosine serve an important role in determining the selectivity between the two similar cations $\mathrm{Rb}^{+}$and $\mathrm{K}^{+}$. However, this amino acid alone cannot explain the entire selectivity. The reverse mutation F66Y in PBCV1$\mathrm{Kcv}$ does not cause a complete reversion of $\mathrm{Rb}^{+} / \mathrm{K}^{+}$selectivity. But both parameters $G_{\mathrm{Rb}} / G_{\mathrm{K}}$ and $\Delta E_{\mathrm{rev}}$ change in the mutant in a direction that is consistent with a reduced selectivity of the channel for $\mathrm{Rb}^{+}$over $\mathrm{K}^{+}$; while the replacement of $\mathrm{K}^{+}$by $\mathrm{Rb}^{+}$causes a mean shift of the reversal voltage in the wild-type of $+10 \mathrm{mV}\left(E_{\text {rev }} \mathrm{K}^{+}=-21.39 \pm 0.70 \mathrm{mV} ; E_{\text {rev }} \mathrm{Rb}^{+}=-11.23 \pm 1.06\right.$ $\mathrm{mV}, n=5)$, the same operation results only in a $+6 \mathrm{mV}$ shift in the mutant highlighted by the enlargement of Figure 5(D) $\left(E_{\text {rev }}\right.$ $\mathrm{K}^{+}=-19.97 \pm 0.31 \mathrm{mV} ; E_{\mathrm{rev}} \mathrm{Rb}^{+}=-14.07 \pm 0.39 \mathrm{mV}, n=5$ ). Also, while the $G_{\mathrm{Rb}} / G_{\mathrm{K}}$ ratio is 1.8 in the wild-type channel, it is reduced to 1.5 in the mutant (Table 1).

Altogether these results are consistent with the idea that phenylalanine in the selectivity filter favors $\mathrm{Rb}^{+}$over $\mathrm{K}^{+}$conductance. However, the data also indicate that the overall selectivity of a filter can only be understood in the context of other structural parts of the channel protein.

\section{Conclusion}

The present results show that a $\mathrm{Kcv}$ protein from chlorella virus ATCV-1, which has the hallmarks of a $\mathrm{K}^{+}$channel, forms a functional $\mathrm{K}^{+}$channel. Even though the monomer is only 82 amino acids long it still forms a tetramer. This tetrameric channel has many features typical of more complex $\mathrm{K}^{+}$channels. ATCV-1 $\mathrm{Kcv}$ can discriminate between cations and it has some voltagedependent features; furthermore, ATCV-1 Kcv has a distinct voltage-dependent sensitivity to typical $\mathrm{K}^{+}$channel blockers such as $\mathrm{Ba}^{2+}$ and $\mathrm{Cs}^{+}$. All of these functional features must be inherent in the basic structure of this miniature channel protein. A comparison of the ATCV-1 Kcv functions with another viral channel, PBCV-1 Kcv, indicates that it differs significantly because it is more permeable to $\mathrm{K}^{+}$than $\mathrm{Rb}^{+}$. This result can be partially explained by a tyrosine residue in the ATCV-1 KcV selectivity filter; in contrast PBCV-1 Kcv has a phenylalanine.

\section{Acknowledgments}

We thank Dan Minor (University of California at San Francisco) for the mutant yeast strain SGY1528 and for help with the complementation protocol.

This work was partially supported by the Public Health Service grant number GM32441 and the National Institutes of Health grant number P20RR15635 from the COBRE program of the National Center of Research Resources to J. L. V. E.; by [grant number 2005052099 PRIN 2005] the Ministero dell' Università e Ricerca; by project EDICT (European Drug Initiative on Channels and Transporters) EU PF7 [grant number 201924] to A. M.; and by a grant from the Deutsche Forschungsgemeinschaft to $\mathrm{G}$. T.

\section{References}

1 Iyer, L. M., Aravind, L. and Koonin, E. V. (2001) Common origin of four diverse families of large eukaryotic DNA viruses. J. Virol. 75, $11720-11734$

2 Iyer, L. M., Balaji, S., Koonin, E. V. and Aravind, L. (2006) Evolutionary genomics of nucleo-cytoplasmic large DNA viruses. Virus Res. $117,156-184$

3 Raoult, D., Audic, S., Robert, C., Abergel, C., Renesto, P., Ogata, H., La Scola, B., Suzan, M. and Claverie, J.-M. (2004) The 1.2-megabase genome sequence of Mimivirus. Science 306, 1344-1350

4 Villarreal, L. P. (2005) Viruses and the Evolution of Life. , American Society Microbiology Press, Washington, DC

5 Dunigan, D. D., Fitzgerald, L. A. and Van Etten, J. L. (2006) Phycodnaviruses: a peek at genetic diversity. Virus Res. 117, 119-132
6 Van Etten, J. L. (2009) The Phycodnaviridae: the story of how tiny giants rule the world. Lesser Known Large dsDNA Viruses pp. 1-42, , Springer, Berlin

7 Van Etten, J. L. (2003) Unusual life style of giant chlorella viruses. Annu. Rev. Genet. 7, 153-195

8 Maramorosch, K. and Shatkin, A. J. (2006) Chlorella viruses. Advances in Virus Research Volume 66 pp. 293-340, , Elsevier,

9 Plugge, B., Gazzarrini, S., Nelson, M., Cerana, R., Van Etten, J. L., Derst, C., DiFrancesco, D., Moroni, A. and Thiel, G (2000) A potassium channel protein encoded by chlorella virus PBCV-1. Science 287, 1641-1644

10 Gazzarrini, S., Severino, M., Lombardi, M., Morandi, M., DiFrancesco, D., Van Etten, J. L., Thiel, G. and Moroni, A. (2003) The viral potassium channel Kcv: structural and functional features. FEBS Lett. 552, 12-16

11 Moroni, A., Viscomi, C., Sangiorgio, V., Pagliuca, C., Meckel, T., Horvath, F., Gazzarrini, S., Valbuzzi, P., Van Etten, J. L., DiFrancesco, D. and Thiel, G. (2002) The short N-terminus is required for functional expression of the virus-encoded miniature $\mathrm{K}^{+}$channel Kcv. FEBS Lett. 530, 65-69

12 Pagliuca, C., Goetze, T. A., Wagner, R., Thiel, G., Moroni, A. and Parcej, D. (2007) Molecular properties of $\mathrm{Kcv}$, a virus encoded $\mathrm{K}^{+}$ channel. Biochemistry 46, 1079-1090

13 Kang, M., Moroni, A., Gazzarrini, S., DiFrancesco, D., Thiel, G., Severino, M. and Van Etten, J. L. (2004) Small potassium ion channel proteins encoded by chlorella viruses. Proc. Natl. Acad. Sci. U.S.A. 101, 5318-5324

14 Gazzarrini, S., Kang, M., Van Etten, J. L., DiFrancesco, D., Tayefeh, S., Kast, S. M., Thiel, G. and Moroni, A. (2004) Long distance interactions within the potassium channel pore are revealed by molecular diversity of viral proteins. J. Biol. Chem. 279, 28443-28449

15 Gazzarrini, S., Kang, M., Epimashko, S., Van Etten, J. L., Dainty, J., Thiel, G. and Moroni, A. (2006) Chlorella virus MT325 encodes water and potassium channels that interact synergistically. Proc. Natl. Acad. Sci. U.S.A. 103, 5355-5360

16 Bubeck, J. A. and Pfitzner, A. J. (2005) Isolation and characterization of a new type of chlorovirus that infects an endosymbiotic Chlorella strain of the heliozoon Acanthocystis turfacea. J. Gen. Virol. 86, 2871-2877

17 Fitzgerald, L. A., Graves, M. V., Li, X., Hartigan, J., Pfitzner, A. J., Hoffart, E. and Van Etten, J. L. (2007) Sequence and annotation of the 288-kb ATCV-1 virus that infects an endosymbiotic Chlorella strain of the heliozoon Acanthocystis turfacea. Virology 362, 350-361

18 Minor, D. L., Masseling, S. J., Jan, Y. N. and Jan, L. Y. (1999) Transmembrane structure of an inwardly rectifying potassium channel. Cell 96, 879-891

19 Chatelain, F. C., Alagem, N., Xu, Q., Pancaroglu, R., Reuveny, E. and Minor, D. L. (2005) The pore helix dipole has a minor role in inward rectifier channel function. Neuron 47, 833-843

20 Doyle, D. A., Morais-Cabral, J., Pfuetzner, R. A., Kuo, A., Gulbis, J. M., Cohen, S. L., Chait, B. T. and MacKinnon, R. (1998) The structure of the potassium channel: molecular basis of $\mathrm{K}^{+}$conduction and selectivity. Science 280, 69-77

21 Hille, B. (1992) Ionic Channels of Excitable Membranes. (2nd ed.), Sinauer Associates, Sunderland, MA

22 Eisenman, G. and Horn, R. (1983) Ionic selectivity revisited: the role of kinetic and equilibrium processes in ion permeation through channels. J. Membr. Biol. 76, 197-225

23 Tayefeh, S., Kloss, T., Kreim, M., Gebhardt, M., Baumeister, D., Hertel, B., Richter, C., Schwalbe, H., Moroni, A., Thiel, G. and Kast, S. M. (2009) Molecular dynamics simulation of the cytosolic mouth in Kcv-type potassium channels. Biophys. J. 96, 485-498

24 Brickmann, J., Goetze, T., Heiden, W., Moeckel, G., Reiling, S., Vollhardt, H. and Zachmann, C.-D. (1995) Interactive visualization of molecular scenarios with MOLCAD/SYBYL. Data Visualization in Molecular Science: Tools for Insight and Innovation (Bowie J. E., eds.), pp. 83-97, , Addison-Wesley, Reading, MA

25 Marti-Renom, M. A., Stuart, A., Fiser, A., Sánchez, R., Melo, F. and Sali, A. (2000) Comparative protein structure modeling of genes and genomes. Annu. Rev. Biophys. Biomol. Struct. 29, 291-325

26 Guizouarn, H., Gabillat, N., Motais, R. and Borgese, F. (2001) Multiple transport functions of a red blood cell anion exchanger, tAE1: its role in cell volume regulation. J. Physiol. 535, 497-506 
A
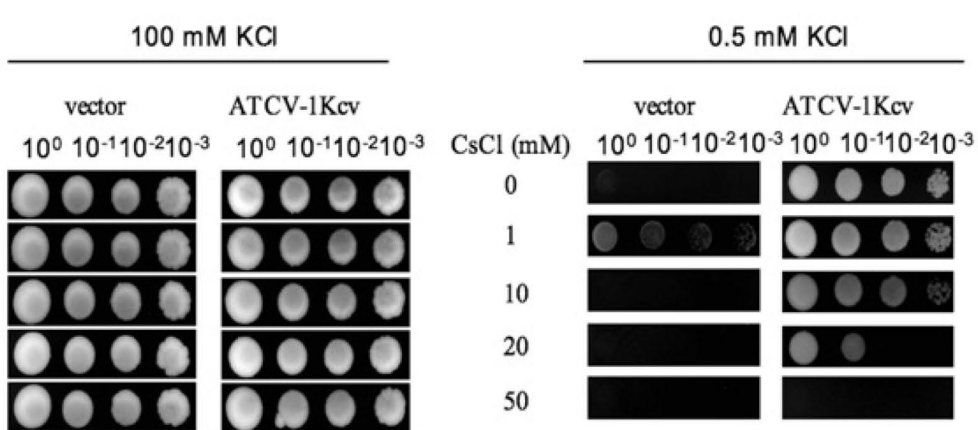

B

C
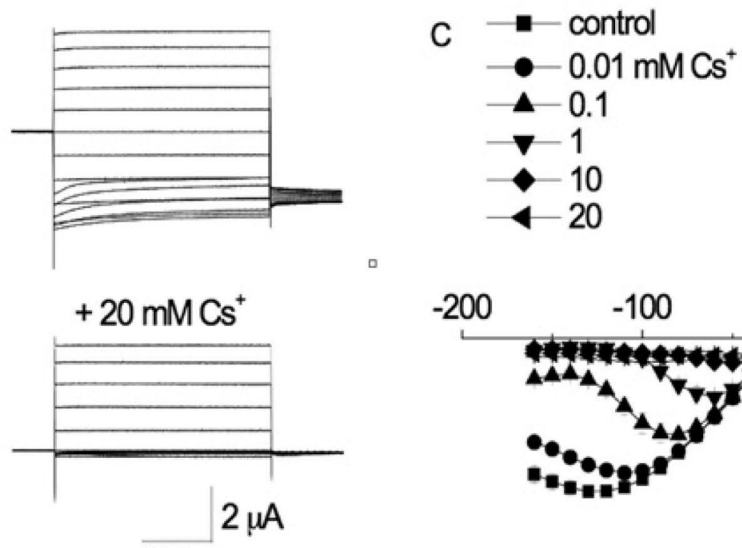

$200 \mathrm{~ms}$
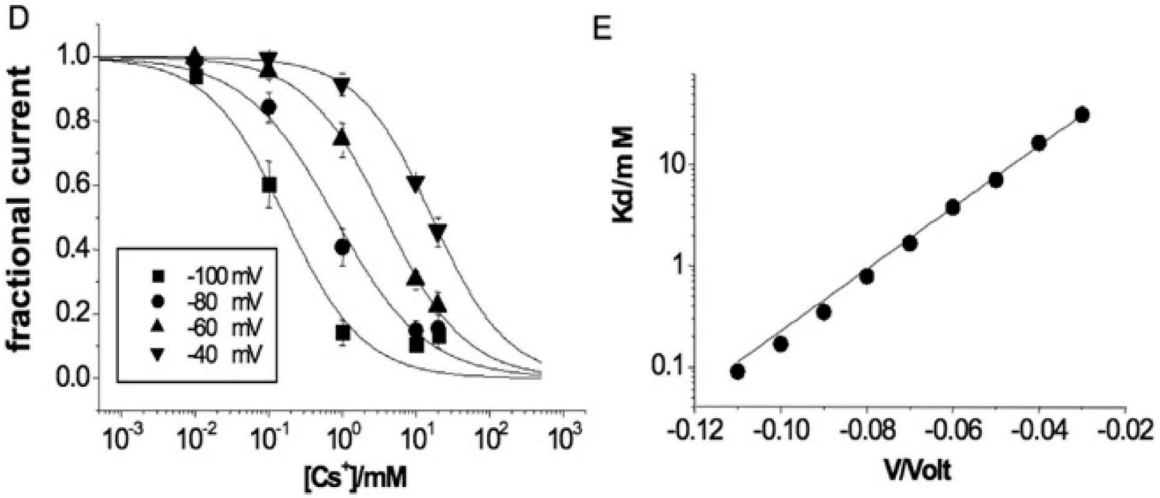

Figure S1. ATCV-1 Kcv is blocked by external $\mathrm{Cs}^{+}$. (A) Complementation assay performed on a $\Delta$ trk1, $\Delta$ trk2 yeast mutant transformed with empty vector (control) or ATCV-1 Kcv. Yeast growth was tested in the presence of the indicated $\mathrm{Cs}^{+}$concentrations. (B) Effect of $20 \mathrm{mM} \mathrm{Cs}{ }^{+}$on ATCV$1 \mathrm{Kcv}$ currents recorded in $50 \mathrm{mM} \mathrm{K}^{+}$. (C) Mean normalized $I / V$ relationship of ATCV-1 Kcv currents recorded at different [Cs $\left.{ }^{+}\right]_{\text {out }}$ values. Normalization was performed at the current value of $-100 \mathrm{mV}$ to allow comparison of different oocytes $(n=5)$. Steady-state current values $\left(I_{\mathrm{ss}}\right)$ are expressed in arbitrary units (a.u.). When not visible, error bars ( \pm S.E.M.) are smaller than symbols. (D) Dose-response curves obtained by plotting the fractional current, $I_{\mathrm{f}}$, as a function of $\left[\mathrm{Cs}^{+}\right]_{\text {out }}$. Curves were fitted with the following Hill equation: $I_{\mathrm{f}}=K_{\mathrm{d}}{ }^{n} /\left(K_{\mathrm{d}}{ }^{n}+\left[\mathrm{Ba}^{2+}\right]^{n}\right)$ fixing $n=1 . K_{\mathrm{d}}$ $=0.15,0.75,4.1$, and $15.9 \mathrm{mM}$ at $-100,-80,-60$, and $-40 \mathrm{mV}$ respectively. (E) Semi-logarithmic plot of $K_{\mathrm{d}}$ against the membrane potential. $K_{\mathrm{d}}$ was obtained from the dose-response curve obtained from data plotted in (C), extending the analysis to potentials not shown in (D). Lines drawn by a least-square fitting. $K_{\mathrm{d}}$ decreased e-fold for $31 \mathrm{mV}$ hyperpolarization. 


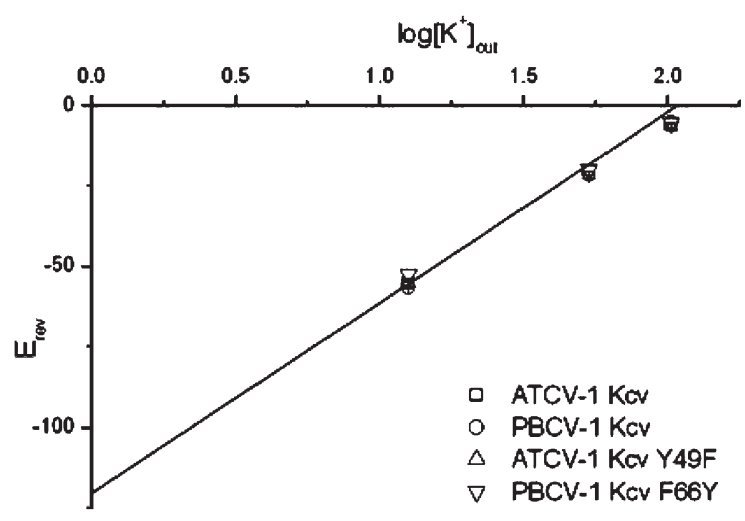

Figure S2. Potassium selectivity of wild-type and mutant Kcv channels. Current reversal potentials $\left(E_{\text {rev }}\right)$ obtained in 10,50 , and $100 \mathrm{mM}$ external

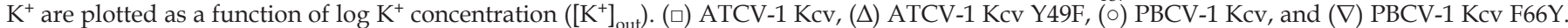
Mean values \pm S.E.M. ( $n=3$ for ATCV-1 Kcv and $n=5$ for the other three channels). The plotted line represents the theoretical Nernst equation $E_{\mathrm{K}}$ $=R T / z F \ln \left[\mathrm{K}^{+}\right]_{\text {out }} /\left[\mathrm{K}^{+}\right]_{\text {in }}[21]$ with a slope of $59.2 \mathrm{mV}$, assuming that in oocytes $\left[\mathrm{K}^{+}\right]_{\text {in }}=108.6 \mathrm{mM}[26]$. 